\title{
LEI DE IMPROBIDADE ADMINISTRATIVA BRASILEIRA: MECANISMO PREVENTIVO À BOA ADMINISTRAÇÃO PÚBLICA?
}

\section{THE BRAZILIAN LAW ON ADMINISTRATIVE IMPROBITY: A PREVENTIVE MECHANISM FOR GOOD PUBLIC ADMINISTRATION?}

\begin{abstract}
Patrícia MARIa Seger de Camargo
Mestre em Letras pela Universidade Federal do Rio Grande do Sul (UFRGS). Aluna do Curso de Especialização Gestão Pública, na Universidade Estadual do Rio Grande do Sul (UERGS). Porto Alegre, RS, Brasil.

patricia.seger@yahoo.com.br

Celmar CorrêA de Oliveira

Doutorado em Recursos Hidricos e Saneamento Ambiental. Universidade Federal do Rio Grande do Sul (UFRGS). Professor Adjunto da Universidade Estadual do Rio Grande do Sul. Porto Alegre, RS, Brasil. celmaroliv@gmail.com
\end{abstract}

\begin{abstract}
RESUMO
A pesquisa versa sobre a Lei $8.429 / 92$ e analisa sua efetividade na prevenção de atos de improbidade. Pretende verificar se a Lei de Improbidade Administrativa contribui para a construção de agentes orientados a práticas administrativas sob o enfoque ético-moral, aspecto fundamental à boa Administração Pública. Analisa-se a moralidade administrativa, ética pública e probidade, aspectos delineadores do sistema jurídico de proteção à probidade administrativa, instaurado a partir da Constituição Federal de 1988. Mediante a análise da sistemática de funcionamento da Lei $8.429 / 92$, verifica-se o alcance do que seja improbidade administrativa e a possibilidade de a Lei configurar mais que um mecanismo de repressão. 0 método de pesquisa adotado é o qualitativo, cujos dados são indiretos. Os resultados mostraram que a CF/1988 tratou do tema de forma inovadora, ensejando um código de condutas que atua na prevenção de práticas ímprobas.
\end{abstract}

Palavras-chave: administração; direito; improbidade; moralidade; probidade.

\begin{abstract}
This research addresses the Brazilian Law 8.429/92 and analyzes its efficacy in preventing acts of misconduct. It intends to verify if the Brazilian law on Administrative Improbity can contribute to developing public agents oriented towards an ethicalmoral practice, a critical aspect to a good public administration. Administrative morality, public ethics and probity are analyzed, three primary aspects of the legal administrative probity system in Brazil, established in the Federal Constitution of 1988. By reviewing Law $8.429 / 92$ we seek to verify the scope of administrative improbity and the possibility of the law dictating more than a repression mechanism. The research method adopted is the qualitative one, through secondary data. The results show that the Brazilian Constitution of 1988 provided an innovative approach on the subject, establishing a code of conduct that assists in the prevention of practices qualified as improbity.
\end{abstract}

Keywords: management; law; misconduct; morality; probity. 


\section{SUMÁRIO}

INTRODUÇAO; 1 MÉTODO E MATERIAIS; 2 PRINCÍPIOS DA MORALIDADE ADMINISTRATIVA E DA PROBIDADE ADMINISTRATIVA; 3 O CONTROLE DA PROBIDADE ADMINISTRATIVA PELO DIREITO ADMINISTRATIVO; 40 SISTEMA DE PROBIDADE ADMINISTRATIVA BRASILEIRO; 50 SISTEMA DE PROBIDADE ADMINISTRATIVA BRASILEIRO É MECANISMO PREVENTIVO À BOA ADMINISTRAÇÃO PÚBLICA?; CONCLUSÃO; REFERÊNCIAS.

\section{INTRODUÇÃO}

A corrupção não é tema novo na história da humanidade e tem adquirido relevo no nosso país nos últimos anos, com destaque especial neste momento pelos sucessivos escândalos divulgados na operação Lava Jato, a qual colocou o país na mídia internacional, em face da má utilização de recursos públicos.

Rizzardo ${ }^{1}$ atenta para o fato de que as preocupações com a corrupção dos governos começaram a despontar na imprensa mundial na década de 1970, nos Estados Unidos da América, com o famoso escândalo do Watergate envolvendo espionagem promovida pelo então Presidente da República Richard Nixon. O tema da moralidade pública tomou vulto internacionalmente, o que acarretou medidas normativas de diversos órgãos internacionais, com vistas à preservação da moralidade pública internacional, tais como a Organização das Nações Unidas, a Organização de Cooperação e Desenvolvimento Econômico e a Organização da Transparência Internacional. No âmbito dos Estados americanos, a Organização dos Estados Americanos em 1996 criou a Convenção Interamericana Contra a Corrupção - CICC estabelecendo princípios que regem a administração proba, da qual o Brasil é signatário.

Em obra sobre o tema da corrupção, Petreluzzi e Rizek Junior ${ }^{2}$ colacionam a crescente preocupação dos Estados modernos em sancionar, do ponto de vista legal, condutas inadequadas de agentes públicos que atinjam recursos públicos. Mencionam as várias abordagens legais nas esferas jurídicas penal, civil e administrativa pelos países, com o objetivo de punir condutas desviantes que atingem o patrimônio público. Listando o arcabouço jurídico brasileiro anticorrupção, inserem a Lei de Improbidade Administrativa, a qual contém relevantes aspectos inovadores no campo do direito administrativo para a repressão das condutas que atentam

\footnotetext{
${ }_{1}^{1}$ RIZZARDO, Arnaldo. Ação civil pública e ação de improbidade administrativa. Rio de Janeiro: Forense, 2014.

2 PETRELLUZZI, Marcos Vinícius; RIZEK JUNIOR, Rubens Naman. Lei anticorrupção: origens, comentários e análise da legislação correlata. São Paulo: Saraiva, 2014.
} 
contra o patrimônio público e os princípios constitucionais que devem reger as atividades da Administração Pública.

Para Rizzardo:

O diploma representa a conscientização dos deveres cívicos em relação ao patrimônio público e significa forte instrumento de combate à corrupção que vem grassando, de modo progressivo, nas últimas décadas, e que vem minando as instituições políticas, os valores morais da nação e a coisa pública. ${ }^{3}$

O Centro Latinoamericano de Adminstración para el Desarrollo - CLAD, criado com respaldo na Assembleia Geral das Nações Unidas em 1972, tem como eixo de seu trabalho a modernização das administrações públicas como um fator estratégico do processo de desenvolvimento econômico e social. Em novembro de 2016, no seu XXI Congresso Internacional, abordou, dentre outras temáticas, a profissionalização, ética e probidade para a construção de um novo servidor.

Pensando nesta temática, o presente trabalho tem como pesquisa central analisar se o sistema jurídico brasileiro de probidade administrativa, introduzido a partir de 1988 pela Constituição Federal ${ }^{4}$ e regulamentado pela Lei Federal 8.429 , de $1992^{5}$, pode contribuir para a prevenção de condutas qualificáveis pelo diploma brasileiro como ímprobas e dessa forma auxiliar a formação de agentes voltados a condutas adequadas no campo da moralidade, para o exercício das atividades da Administração Pública.

Para responder ao questionamento o trabalho tem como objetivo geral analisar o sistema jurídico de probidade administrativa vigente no Brasil e, como objetivos específicos, analisar a definição e/ou função da moralidade e da probidade administrativa. Nesse sentido, procura-se desvelar a origem, o conteúdo e as diferenças entre moralidade e probidade administrativa, bem como o controle do dever de probidade, para, na continuidade, estabelecer o que é no direito administrativo brasileiro improbidade administrativa e se a Lei 8.429/92 produz efeitos preventivos às práticas, no campo da ética.

\footnotetext{
${ }^{3}$ RIZZARDO, Arnaldo. Ação civil pública e ação de improbidade administrativa. Rio de Janeiro: Forense, 2014, p. 370.

4 BRASIL. Constituição (1988). Constituição da República Federativa do Brasil. Brasília, DF: Senado Federal, 1988.

${ }^{5}$ BRASIL. Lei $N^{\circ} 8.429$, de 2 de junho de 1992. Ementa: Dispõe sobre as sanções aplicáveis aos agentes públicos nos casos de enriquecimento ilícito no exercício de mandato, cargo, emprego ou função na administração pública direta, indireta ou fundacional e dá outras providências. Diário Oficial [da] República Federativa do Brasil, Poder Executivo, Brasília, DF, 03 jun. 1992, Seção 1, p. 6995.
} 
O estudo do tema da improbidade administrativa, que abrange o campo central da ética pública, justifica-se em face desta crescente preocupação dos Estados em atacar condutas inadequadas de agentes públicos, que atingem o patrimônio público, este constituído não só de recursos econômicos, mas também de um valor extrapatrimonial que é a moralidade administrativa em si, princípio que orienta qualquer atividade administrativa à satisfação do interesse público. Portanto, o presente trabalho, com a aproximação do campo jurídico ao ético, justifica-se pela intenção de investigar o mecanismo jurídico como um meio preventivo para auxiliar a construção de agentes orientados ao campo ético.

O doutrinador italiano Matarella ${ }^{6}$ alude que políticas públicas e setores administrativos têm de lidar com os riscos de erros profissionais e a necessidade de prevenção. Afirma o autor que a prevenção da corrupção na esfera administrativa deve ser feita em várias frentes, porque há muitos pontos fracos que permitem o deslizamento de negligências. Dentre remédios conhecidos cita, a exemplo, os códigos de conduta para os políticos e as categorias de trabalhadores. Este é o diferencial buscado na presente pesquisa: verificar se a estrutura e a funcionalidade da Lei de Improbidade Administrativa brasileira determinam, além do resultado punitivo, vinculação espontânea dos agentes, de forma a contribuir à prevenção e ao controle prévio de condutas indesejadas à boa Administração Pública.

\section{MÉTODO E MATERIAIS}

A pesquisa almeja auxiliar a compreensão estrutural do sistema de probidade administrativa brasileiro a partir de estudo teórico-jurídico. Visa alcançar profissionais e acadêmicos de gestão pública e de áreas afins, agentes públicos de todas as categorias e hierarquias e pessoas desvinculadas do serviço público. Consiste em estudo teórico de tema específico do direito administrativo e suas novas tendências, para orientar a compreensão da formulação de conceitos, funções e relações que respondam a questão pesquisada. Ou seja, quanto à existência de funcionalidade preventiva na Lei de Improbidade, visando à formação no campo da ética administrativa.

Para alcançar o fim proposto, foi adotada uma ordem de estudo das categorias que constroem o percurso da sistematização do modelo de improbidade administrativa adotado no

${ }^{6}$ MATTARELLA, Bernardo Giorgio. Recenti tendenze legislative in materia di prevenzione della corruzione. Giornale di diritto amministrativo. Milano, v. 2, 2012. 
Brasil. Nesse sentido, o estudo inicia com os princípios balizadores para a definição de improbidade, que são a moralidade e a probidade administrativas, levando em conta conceitos, funções e relações. Destarte, o trabalho analisa particularidades de institutos jurídicos e suas inter-relações, levando à compreensão do sistema de probidade administrativa vigente e das complexidades que o tema envolve e desenvolve até chegar à resposta quanto à funcionalidade preventiva da Lei 8.429/92.

Considerando que as variáveis adotadas não visam medir quantitativamente resultados, mas permitir a análise e a compreensão de categorias doutrinárias relacionadas entre si, o procedimento metodológico é qualitativo. Já a pesquisa é fundamentalmente doutrinária, utilizando-se, portanto, documentação indireta.

\section{PRINCÍPIOS DA MORALIDADE ADMINISTRATIVA E DA PROBIDADE ADMINISTRATIVA}

No início do século XX, surge a expressão "moral administrativa" fundada pelo francês Maurice Hariou, indicando regras não escritas na Administração Pública, relacionadas à valorização ética das normas ao lado da legalidade. ${ }^{7} \mathrm{~A}$ ideia de boa administração continha a valorização da finalidade do ato administrativo ao lado do conteúdo legal, como meio para o alcance da satisfação de interesses públicos e como forma de contenção de discricionariedades que pudessem levar a abusos pelos administradores públicos.

Bastos $^{8}$ menciona, em abordagem didática de Marcelo Figueiredo, três fases do desenvolvimento do tema moralidade administrativa. A primeira, a partir de Hauriou, na qual a imoralidade é elemento interno à legalidade. A segunda, influenciada pela anterior, onde nasce o controle sobre os motivos considerados pela Administração Pública e sobre as finalidades dos atos administrativos praticados pelos agentes. A terceira, a que se apresenta sob nova perspectiva, ultrapassando a moralidade exclusiva "da" ou "na" Administração, conquistando o lugar de categoria de direito público subjetivo, a partir de sua transformação em princípio constitucional. Nos dizeres da autora, é o direito público subjetivo do cidadão a um governo honesto que leva a moralidade ao reconhecimento de princípio jurídico, através do qual o Estado

\footnotetext{
${ }^{7}$ OSÓRIO, Fábio Medina. Teoria da Improbidade Administrativa: má gestão: corrupção: ineficiência. São Paulo: Revista dos Tribunais, 2013.

8 BASTOS, Rosaura Moreira Brito. Improbidade Administrativa - conteúdo jurídico e dimensão constitucional. Belo Horizonte: Fórum, 2010, p. 38.
} 
desempenha seu fim de realizar o bem comum, em conformidade a consenso de valores éticos predominantes no momento. É, portanto, uma perspectiva mais ampla, eis que situa a moralidade administrativa na posição de princípio fundamental.

Nesse sentido, Fazzio Júnior colaciona:

Se, antes da Constituição Federal, ainda era possível tratar da moralidade administrativa como componente embutido nas normas, de modo que o ato ilegal, por si só, já traduzia uma conduta imoral de seu autor, o art. 37, caput, da Carta subtraiu as credenciais dessa concepção. Ao instalar, paralelamente, entre os princípios constitucionais regentes da Administração Pública, a legalidade e a moralidade, efetuou insofismável distinção entre ambas e reinscreveu a segunda no direito objetivo brasileiro. ${ }^{9}$

A moralidade administrativa abriu portas à compreensão de que o agente público, mais do que vincular-se à legalidade, deveria observar regras de uma moral administrativa ao desempenhar suas funções. Nessa esteira, Martins Júnior vincula o conteúdo jurídico da moralidade administrativa à finalidade, justificando a imoralidade pelo desvio ou pela ausência de finalidade, somados à ineficácia grosseira do ato administrativo:

Não se pode negar, até mesmo em atenção ao aspecto hereditário-atávico (da formação da sociedade brasileira), que na finalidade se encontra o conteúdo da moralidade administrativa, dado que é da mensuração da compatibilidade do resultado atingido pelo agente público na sua conduta com os fins públicos que a lei, implícita ou explicitamente, estabeleceu que se pode concluir a moralidade ou não da atividade administrativa, campo de cognição superior ao da legalidade. ${ }^{10}$

Todavia, acompanhando os desdobramentos que foram seguindo-se à discussão quanto ao conteúdo da moralidade administrativa, o autor aduz que não se pode atribuir exclusivamente à finalidade a aplicação e compreensão do conteúdo do princípio da moralidade administrativa, haja vista que é pelo exame da finalidade conjuntamente ao motivo e ao objeto do ato que se verifica a compatibilidade do ato administrativo ao princípio da moralidade administrativa. Advoga o autor que há vetores que levam a sua compreensão ao atuarem sobre requisitos do ato administrativo, ampliando a incidência da moralidade e fazendo-a evoluir à barreira da discricionariedade administrativa.

Sobre a matéria discorre Medauar:

\footnotetext{
${ }^{9}$ FAZZIO JÚNIOR, Waldo. Atos de Improbidade Administrativa: doutrina, legislação e jurisprudência. São Paulo: Atlas, 2007, p. 13.

${ }^{10}$ MARTINS JR, Wallace Paiva. Probidade Administrativa. São Paulo: Saraiva, 2009, p. 57.
} 
O princípio da moralidade administrativa é de difícil tradução verbal, talvez porque seja impossível enquadrar em um ou dois vocábulos a ampla gama de condutas e práticas desvirtuadoras das verdadeiras finalidades da Administração Pública. Em geral, a percepção da imoralidade administrativa ocorre no enfoque contextual, ou melhor, ao se considerar o contexto em que a decisão foi ou será tomada. A decisão, de regra, destoa do contexto, e do conjunto de regras de conduta extraídas da disciplina geral norteadora da Administração Pública. ${ }^{11}$

Embora a moralidade administrativa tenha sido alçada a princípio na Constituição Federal do Brasil de 1988 e com isso ganhado eficácia normativa, seu conteúdo na esfera jurídica, tanto na doutrina quanto na aplicação jurisprudencial, ainda é motivo de discussão.

Giacomuzzi $^{12}$ alude a reiterada afirmação de doutrinadores brasileiros quanto a não equivalência entre a moral administrativa e a moral comum, sem, contudo, fazerem clara definição de critérios mínimos balizadores de uma e de outra, que delimite claramente a aplicação do princípio no Direito. Refere o autor de forma crítica que, quando muito, a doutrina tem afirmado que a moralidade administrativa não se confunde com a moral comum e corresponde às regras da boa administração, e que muitos acórdãos refletem essa posição doutrinária sem, da mesma forma, dar qualquer explicação sobre a diferença entre uma e outra, prevalecendo a conveniência e a subjetividade do intérprete.

Essa incerteza, conforme segue ele, vem de há muito sem solução. Menciona o jurista estudos diversos de respeitáveis jusfilósofos desde Kelsen, Perelman, Vázquez e Hart, para os quais a moral comum tem caráter de subjetividade e incerteza, na medida em que possui um relativismo interno pela mudança de valores de tempos em tempos, contrapondo-se ao caráter externo normativo do Direito. De outra parte menciona Valdés, que baseado no pensamento de Bunge, Zimmerling e Klug, mostra uma possível aproximação normativa da moralidade administrativa à moral comum, haja vista que sustenta a possibilidade de um objetivismo ético fundado na satisfação das necessidades básicas das pessoas. 0 critério objetivo seria direitos humanos extraídos das declarações de direitos universais, os quais seriam axiomas constitutivos de um sistema normativo e regulador do conteúdo das normas dos sistemas jurídicos positivos. Nesse caso, moralidade administrativa e moral comum direcionadas ao respeito aos direitos humanos seriam uma mínima positivação. 0 autor cita também acórdãos de diferentes tribunais que mencionam a moralidade administrativa como sendo a imagem da moral comum; o

\footnotetext{
${ }^{11}$ MEDAUAR, Odete. Direito Administrativo Moderno. São Paulo: Revista dos Tribunais, 2010, p. 131.

12 GIACOMUZZI, José Guilherme. A moralidade administrativa e a boa-fé da administração pública (o conteúdo dogmático da moralidade administrativa). São Paulo: Malheiros, 2002.
} 
entrelaçamento objetivo de ambas; a moral comum invocada como parâmetro da moralidade administrativa e, portanto, aproximando uma da outra.

Entretanto, mais importante do precisar e fixar contornos da moralidade administrativa, a Giacomuzzi $^{13}$ interessa delimitar o seu âmbito de ação ou descobrir sua função no ordenamento jurídico. Assim, tomando como base lições de juristas gaúchos, a saber Almiro do Couto e Silva, Judith Martins Costa e especificamente Juarez Freitas, defende-se a posição de que o conteúdo dogmático do princípio da moralidade possui um aspecto objetivo, que se refere à boa-fé objetiva no campo do Direito Público Administrativo, cujo desdobramento é a proteção à confiança legítima dos administrados, pelo cumprimento de deveres de conduta transparente e leal. Mas há também um aspecto subjetivo, que tutela os deveres de honestidade e lealdade, entendidos como deveres de probidade exigíveis na lei de improbidade administrativa.

Nesse sentido, ele reforça a crítica de Medina Osório à absorção e ao esgotamento da moralidade administrativa pela doutrina do desvio de finalidade, no intuito de dar à moralidade administrativa concepção mais objetiva, abrindo portas à impunidade, haja vista que nesta orientação o exame da conduta do agente público recai sobre sua intencionalidade. Refere a busca desta objetividade, por Medina Osório, na ideia de que na base da moralidade administrativa estariam conceitos de razoabilidade, interesse público e proporcionalidade, cujo raciocínio seria pautado na necessidade de formulação de padrões médios de condutas exigíveis aos agentes públicos, de modo que a moralidade administrativa é princípio que adquire função complementar à legalidade. ${ }^{14}$

Fazzio Júnior ${ }^{15}$ afirma que operando por meios legais, a moralidade administrativa é aferida pela adequação entre meios e fins, pelo fato de não se desviar da finalidade constante da lei, a qual reflete o interesse público. Entretanto, a moralidade também se refere ao conteúdo ético do trabalho administrativo, a partir da indisponibilidade do interesse maior da coletividade. Portanto, é princípio geral de Direito que recomenda a observância das regras da

\footnotetext{
${ }^{13}$ GIACOMUZZI, José Guilherme.. A moralidade administrativa e a boa-fé da administração pública (o conteúdo dogmático da moralidade administrativa). São Paulo: Malheiros, 2002.

${ }^{14}$ GIACOMUZZI, José Guilherme.. A moralidade administrativa e a boa-fé da administração pública (o conteúdo dogmático da moralidade administrativa). São Paulo: Malheiros, 2002 apud OSÓRIO, Fábio Medina. 0 uso da máquina administrativa e as finalidades privadas dos agentes públicos: observações sobre a Lei 9.504/1997 à luz da Constituição Federal de 1988. Revista do Ministério Público do Rio Grande do Sul, n. 41, Porto Alegre, jan./jul. 2000.

${ }^{15}$ GIACOMUZZI, José Guilherme.. A moralidade administrativa e a boa-fé da administração pública (o conteúdo dogmático da moralidade administrativa). São Paulo: Malheiros, 2002 apud OSÓRIO, Fábio Medina. 0 uso da máquina administrativa e as finalidades privadas dos agentes públicos: observações sobre a Lei 9.504/1997 à luz da Constituição Federal de 1988. Revista do Ministério Público do Rio Grande do Sul, n. 41, Porto Alegre, jan./jul. 2000.
} 
melhor administração. A moralidade predetermina a seletividade administrativa dos meios $e$ fins. $^{16}$

Ressalta ele que, da leitura objetiva da atividade administrativa, extrai-se o binário legal/ilegal, enquanto que a atividade pública não se biparte em ética/antiética, porque o que existe de fato são condutas éticas ou antiéticas de pessoas naturais - os agentes públicos - eis que valores morais são atributos de pessoas físicas. É por isso que a improbidade administrativa é revelada na projeção de atos de agentes públicos.

Nesse diapasão, destaca o autor que o ato administrativo é manifestação volitiva de quem o pratica, realizada em nome de todos. A moralidade, portanto, adquire lugar de conexão ética entre agentes públicos e o exercício de suas funções. Importante de ressaltar que o mesmo autor aduz que o estudo produtivo da improbidade administrativa é o que se debruça sobre as condutas dos agentes públicos, porque estes conferem maior ou menor moralidade às posições administrativas ocupadas e às condutas expressivas de probidade e proeminência dos direitos republicanos ou sua denegação.

Embora a Constituição Federal de 1988, no art. 37, tenha utilizado os termos moralidade administrativa e improbidade administrativa para referir o mesmo fenômeno jurídico, a maioria de doutrinadores trata da moralidade administrativa como mais ampla que a probidade administrativa, sob o prisma de que esta última deriva da moralidade. ${ }^{17}$

Em obra específica sobre probidade administrativa, Wallace Paiva Martins Júnior colaciona a definição de deveres de agente público e o conceito de probidade a partir de substitutivo do Senado Federal ao Projeto de Lei 1446/91, que deu origem à Lei Federal 8.429/92, o qual foi rejeitado na Câmara de Deputados em sede de revisão. Referia o art. $5^{\circ}$ : “o dever de probidade dos agentes públicos compreende a obrigação de exercício do mandato, cargo, emprego, função ou atividade com o exclusivo propósito de realizar o interesse coletivo, preservando a dignidade das instituições e a incolumidade do patrimônio público". ${ }^{18}$

Assim, advoga o autor que tais definições possibilitam vislumbrar no princípio da probidade administrativa um conteúdo próprio, decorrente do princípio da moralidade

\footnotetext{
${ }^{16}$ GIACOMUZZI, José Guilherme.. A moralidade administrativa e a boa-fé da administração pública (o conteúdo dogmático da moralidade administrativa). São Paulo: Malheiros, 2002 apud OSÓRIO, Fábio Medina. 0 uso da máquina administrativa e as finalidades privadas dos agentes públicos: observações sobre a Lei 9.504/1997 à luz da Constituição Federal de 1988. Revista do Ministério Público do Rio Grande do Sul, n. 41, Porto Alegre, jan./jul. 2000, p. 15.

${ }^{17}$ BAHENA, Kelen Cristiane Diogo. O princípio da moralidade administrativa e seu controle pela Lei de Improbidade. Curitiba: Juruá, 2010, p. 114.

${ }^{18}$ MARTINS JR, Wallace Paiva. Probidade Administrativa. São Paulo: Saraiva, 2009, p. 114.
} 
administrativa e informado pelos mesmos valores que incidem neste último. No entanto, aduz que a probidade adquire contorno próprio, na medida em que possui função instrumentalizadora da moralidade administrativa, atuando sensivelmente à garantia de eficácia - ainda que no sentido negativo, de proibição ou vedação - dos princípios da Administração Pública. Portanto, a probidade carrega o conceito de dever do agente público, orientado pelo senso ético, que por sua vez ressalta do princípio da moralidade administrativa.

Nessa mesma esteira caminham as lições de Martins:

(...), afirma-se que da moralidade administrativa exsurgem deveres de conduta que explicitam a exigência de correção (lealdade, seriedade, zelo, boa-fé, sinceridade e motivação) do agente público na expedição de atos administrativos e na conservação do patrimônio público, sob pena de sanção. Nesse passo, se a moralidade administrativa pode acarretar apenas a anulação de ato administrativo, será a probidade que acoimará ao agente a sanção pela quebra dessa correção exigida. Portanto, a probidade agregou à moralidade administrativa um caráter repressor e até econômico, conforme se vê da sanção civil, nos termos da Lei 8.429/1992. ${ }^{19}$

Ao elaborar uma proposta teórica da improbidade administrativa, Osório ${ }^{20}$, tratando da disciplina da ética, distingue a ética pública da ética privada, na medida em que esta última vincula-se à moral crítica, cujas sanções são internas e autônomas, enquanto a ética pública supõe deveres públicos distintos dos deveres privados das pessoas. No que tange à ética pública, alude o autor uma disciplina ético-normativa das responsabilidades, que se opõe à tendência de negar responsabilidade às pessoas. ${ }^{21}$ Afirma que a função dessa disciplina específica e peculiar é de preservar os elementos essenciais da ideia tradicional de responsabilidade pessoal contra as pressões da vida institucional. Assim, encaminha o estudo da improbidade para uma perspectiva ético-normativa do direito constitucional, administrativo e punitivo em suas vertentes, no qual está inserida a proteção da probidade.

Colaciona Manoel de Oliveira Franco Sobrinho:

De um modo geral, a moralidade administrativa passou a constituir pressuposto de validade de todo ato da Administração Pública. Não se trata, contudo, da moral comum, mas sim da moral jurídica. E para a qual prevalece a necessária

\footnotetext{
${ }^{19}$ MARTINS, Fernando Rodrigues. Controle do Patrimônio Público: comentários à Lei de Improbidade Administrativa. São Paulo: RT, 2010, p. 187.

${ }^{20}$ OSÓRIO, Fábio Medina. Teoria da Improbidade Administrativa: má gestão: corrupção: ineficiência. São Paulo: Revista dos Tribunais, 2013.

${ }^{21}$ OSÓRIO explica que a ética é a disciplina normativa da atuação dos servidores orientados a satisfazer os interesses gerais da comunidade, a partir do setor público, com assento na lição de García de Enterría, o qual consagra a ética de responsabilidade na reforma da Administração Pública inglesa na década de 1990.
} 
distinção entre o bem e o mal, o honesto e o desonesto, o justo e o injusto, o conveniente e o inconveniente, o oportuno e o inoportuno, o legal e o ilegal. Não obedecendo $\mathrm{o}$ ato administrativo somente à lei jurídica. ${ }^{22}$

Bahena $^{23}$ advoga que a relegitimação ética tem ocupado o pensamento de filósofos, pensadores e juristas de todo o mundo desde os tempos mais remotos, eis que a influência da moral no direito é cada vez mais sentida, especialmente no direito público. Nessa mesma esteira, Fazzio Júnior, ao falar sobre a moralidade administrativa, afirma que "são intensas as relações da moral com o direito, no plano administrativo". ${ }^{24}$

Freitas $^{25}$ contribui de forma definitiva ao mencionar que o princípio da moralidade, no campo administrativo, não deve ser entendido como "singelo conjunto de regras deontológico, extraídas da disciplina interna da Administração", mas que diz "com os padrões éticos de uma determinada sociedade", sintetizando a convergência das teses dos autores examinados neste artigo e estabelecendo um elo com os princípios da Administração Pública, com assento constitucional.

A Constituição de 1988 ultrapassou a exigência da legalidade ao administrador público ao positivar condutas que impõem o cumprimento também de regras morais, sob sanções previstas constitucionalmente. A Constituição, com isso, estabeleceu em capítulo próprio à Administração Pública o dever de probidade, orientado pela moralidade administrativa.

Fazzio Júnior ${ }^{26}$ bem esclarece que o sistema constitucional atua como um campo de força para que a ordem jurídica fique sob seu império. Em face disso, a Lei de Improbidade Administrativa, no artigo $4^{\circ}$, trouxe para a dimensão legislativa ordinária os princípios constitucionais pautados nas diretrizes do artigo 37 da Constituição Federal de 1988, incorporando a concretização de tais princípios por meio de regras que demandam cumprimento e diligência a seus destinatários, os agentes públicos de qualquer nível ou hierarquia.

\footnotetext{
${ }^{22}$ Apud PAZAGLINI FILHO, Marino; ROSA, M. F. E; FAZZIO JÚNIOR, Waldo. Improbidade Administrativa: aspectos jurídicos da defesa do patrimônio público. São Paulo: Atlas, 1999, p. 55.

${ }_{23}$ BAHENA, Kelen Cristiane Diogo. O princípio da moralidade administrativa e seu controle pela Lei de Improbidade. Curitiba: Juruá, 2010.

${ }^{24}$ Ibidem. p. 12.

${ }^{25}$ FREITAS, Juarez. O Controle dos Atos Administrativos e os princípios fundamentais. 2. ed., São Paulo: Malheiros, 1999 , p. 69.

${ }^{26}$ FAZZIO JÚNIOR, Waldo. Atos de Improbidade Administrativa: doutrina, legislação e jurisprudência. São Paulo: Atlas, 2007.
} 


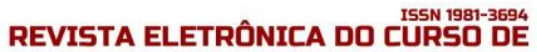

\section{O CONTROLE DA PROBIDADE ADMINISTRATIVA PELO DIREITO ADMINISTRATIVO}

A atitude punitiva do Estado, na esfera administrativa, pode ocorrer de duas formas. Sob o prisma da sujeição especial, o Estado age contra o agente público por intermédio do órgão ao qual este último está vinculado. Neste caso, o bem tutelado é o serviço interno da Administração Pública, sob regime e responsabilidade disciplinar. Nas palavras de Simão Neto, é “um poder com fins pedagógicos, voltado a tutelar o bom desenvolvimento das funções ou o serviço que se desempenha, podendo chegar ao extremo, que é o rompimento do vínculo jurídico de trabalho". ${ }^{27}$

Sob outro aspecto, o Estado exerce seu poder punitivo por meio de um regime de sujeição geral. Nesta segunda forma, a manifestação do poder de punir considera a submissão dos cidadãos a um ser soberano, fruto da própria ideia de Estado. É a situação em que se encontra toda e qualquer pessoa, independentemente de possuir vínculo particular com a Administração Pública. o jus puniendi é materializado pelo Judiciário e o bem tutelado não é mais o serviço interno da Administração, mas valores externos a ele, que acarretam interesse a toda a sociedade. ${ }^{28}$

Sob o prisma da sujeição geral, a Constituição Federal brasileira de 1988 estabeleceu responsabilidades concretas no âmbito do direito administrativo e não penal, para controle e proteção da probidade administrativa, com o jus puniendi a cargo do Judiciário. E tais responsabilidades não só aos agentes públicos, mas estendidas a toda e qualquer pessoa, física ou jurídica, que pratique atos de improbidade administrativa, conforme estabelece o $\S 4^{\circ}$, do artigo 37:

Art. 37. A administração pública direta e indireta de qualquer dos Poderes da União, dos Estados, do Distrito Federal e dos Municípios obedecerá aos princípios de legalidade, impessoalidade, moralidade, publicidade e eficiência e, também, ao seguinte:

[...]

$\S 4^{\circ}$ Os atos de improbidade administrativa importarão a suspensão dos direitos políticos, a perda da função pública, a indisponibilidade dos bens e o ressarcimento ao erário, na forma e gradação previstas em lei, sem prejuízo da ação penal cabível. ${ }^{29}$

\footnotetext{
${ }^{27}$ SIMÃO NETO, Calil. Improbidade Administrativa: teoria e prática. Leme: J. H. Mizuno, 2014, p. 73.

${ }^{28}$ Ibidem. p. 73.

29 BRASIL. Constituição (1988). Constituição da República Federativa do Brasil. Brasília, DF: Senado Federal, 1988.
} 
A Constituição Federal brasileira, com tal dispositivo, determinou a juridicização de valores éticos necessários ao alcance de anseios e direitos de toda a sociedade, por meio da fixação de responsabilidades por atos de improbidade administrativa e sanções concretas, sob regime punitivo administrativo, a cargo do Judiciário. Alude Arnaldo Rizzardo que "a última e vigente Lex Mater, em seu art. 37, § $4^{\circ}$, trazendo substanciais mudanças, introduziu o controle dos atos administrativos e deu mais extensão ao sentido de improbidade, com graves cominações no seu combate". ${ }^{30}$

Com efeito, mostra o autor que a Constituição da República de 1891 definia como crimes de responsabilidade os atos do Presidente da República que atentassem contra a probidade da administração. A Carta de 1939 enquadrava como de responsabilidade os atos do Presidente da República, definidos em lei, que pudessem caracterizar improbidade. A Constituição de 1937 previa regras sobre a integridade do erário e previa punições aos crimes de responsabilidade administrativa.

Segue o autor dizendo que, embora a Constituição de 1946 tenha inserido importante regra de punição contra atos de improbidade, estabelecendo que "a lei disporá sobre o sequestro e o perdimento de bens, no caso de enriquecimento ilícito, por influência ou com abuso de cargo ou função pública, ou de emprego em entidade autárquica"31, reeditada na Constituição de 1967 com as alterações das Emendas 1/69 e 11/78, as duas leis ordinárias que despontaram à concretização das normas constitucionais - Lei 3.164/57 e Lei 3.502/58 revelaram-se frágeis à função, eis que não contemplavam situações reveladoras de lesão ao erário nem previam sanções fortes para as condutas lesivas aos princípios e deveres administrativos. A regulamentação previa mais figuras penais para a obtenção de vantagem ilícita. Além do que, refere o autor, embora o sistema jurídico de tais leis assegurasse a legitimidade do Ministério Público para a propositura de ação, objetivando o sequestro e a perda de bens resultantes de atos lesivos ao patrimônio público, raros foram os casos. Isto porque os atos dos Poderes Públicos gozavam de certa presunção de legalidade e de licitude, ainda que carregados de arbitrariedade.

Destaca Fábio Medina Osório que a Constituição Federal de 1988 inovou, na medida em que a improbidade administrativa foi tratada como ilícito de responsabilidade e ilícito extrapenal, num movimento inovador e desprendido da tradição constitucional. Ele refere:

\footnotetext{
${ }^{30}$ RIZZARDO, Arnaldo. Ação civil pública e ação de improbidade administrativa. Rio de Janeiro: Forense, 2014, p. 369.

31 Ibidem. p. 369.
} 
É novidade histórica, sem embargo, a previsão da improbidade no art. 37, par. 4, da CF, pela forma de tratamento dispensado à matéria. Destacamos o modelo brasileiro, no tratamento da improbidade administrativa, à luz do direito administrativo, com um modelo centralizador, partindo da Constituição Federal, uma forma original de encarar o problema, rompendo a tradição mais ou menos linear que as Constituições antecessoras marcaram, na oscilação entre a perspectiva penal e a perspectiva puramente ressarcitória, encarada também como cível, além do enfoque infraconstitucional sempre voltado ao campo disciplinar. ${ }^{32}$

Importante é a explicação de Mattarella ${ }^{33}$ sobre a noção diferenciada entre a corrupção administrativa e a penal, posto que a primeira possui noção mais ampla já que não se refere apenas ao comportamento criminoso, mas também a atos que são fonte de responsabilidade para outro tipo, tais como: conflitos de interesse, nepotismo, clientelismo, partidarismo, ocupação de cargo público, o absentismo, o desperdício. São noções juridicamente relevantes. Refere o doutrinador italiano que, sendo noção mais ampla, é mais ampla também a lei administrativa articulada à estratégia de combate à corrupção. Enquanto a corrupção crime é travada principalmente pela repressão, as formas de negligência relevantes para o direito administrativo são travadas com mecanismos organizacionais e processuais, atuando principalmente nos controles com foco na ética e na formação de pessoal.

A relação entre a corrupção e o direito administrativo é complexa e multifacetada. Diz ainda o autor que a consciência da importância da estratégia de prevenção da corrupção administrativa anda de mãos dadas com a insuficiente consciência da repressão criminal, haja vista que o resultado normal dos julgamentos por corrupção é a prescrição e a execução das penas de prisão é muito rara.

Neste contexto, diz ele, a prevenção administrativa para remediar a falha do processo criminal é mais eficaz do que um longo e complexo processo criminal por corrupção em atos oficiais ou licitações fraudulentas. Aduz ainda que o julgamento criminal é projetado para determinar a responsabilidade individual, não para investigar grandes fenômenos ilegais. Investigações e processos penais são construídos para apurar fatos próprios e não de eventos do sistema. Enquanto o direito penal é a mão pesada do ordenamento, os instrumentos do direito administrativo devem ser usados de modo mais difuso.

\footnotetext{
32 OSÓRIO, Fábio Medina. Teoria da Improbidade Administrativa: má gestão: corrupção: ineficiência. São Paulo: Revista dos Tribunais, 2013, p. 98.

${ }_{33}^{33}$ MATTARELLA, Bernardo Giorgio. Recenti tendenze legislative in materia di prevenzione della corruzione. Giornale di diritto amministrativo. Milano, v. 2, 2012.
} 
A regulamentação do novo dispositivo constitucional coube ao legislador federal, por meio da Lei Federal 8.429, de 1992, conhecida como Lei de Improbidade Administrativa - LIA. Sobre o diploma legal expressa Osório:

É possível dizer que a LGIA é um instrumento peculiar, distinto, destinado a cuidar da probidade administrativa, ou seja, a improbidade tipificada como ilícito pelo direito administrativo, não pelo direito penal. Não exclui nem elimina outros instrumentos. Ao contrário, com estribo na Constituição Federal, desempenha um papel normativo especializado e contundente. ${ }^{34}$

Em face dessas inovações constitucionais e legais, que inseriram o direito administrativo em novo ramo do direito administrativo sancionador, especialmente para a proteção da probidade administrativa, extrai-se que a Lei de Improbidade Administrativa deve ser compreendida como código ético-normativo de responsabilização, em um contexto mais amplo que o interna corporis e que orienta quais as condutas poderão ser sancionadas pela tipificação de improbidade administrativa. ${ }^{35}$

\section{SISTEMA DE PROBIDADE ADMINISTRATIVA BRASILEIRO}

A Constituição Federal brasileira de 1988 previu ao ilícito de improbidade administrativa sanções desta natureza, normatizadas por um direito administrativo sancionador, que ao formalizar infrações e penas, a exemplo do direito penal, protegeu bens jurídicos afetos a outras áreas, visando à proteção do dever de probidade administrativa. Constituinte e legislador, através da Lei de Improbidade Administrativa brasileira - LIA, separaram o ramo do direito administrativo sancionador do processo administrativo, redimensionando a sanção administrativa não somente ao poder administrativo sancionador, mas situando-a também no processo judicial, em face da sujeição geral a que toda e qualquer pessoa está submetida.

Todavia, um ilícito de improbidade administrativa pode simultaneamente ser tipificado na Lei de Improbidade e no Código Penal, em face dos efeitos diversos que produza. A incidência da Lei de Improbidade Administrativa não exclui outras responsabilidades se do ato, outras, além da administrativa, resultarem.

É importante mencionar que a Lei 8.429/92 veio estruturada na forma de um verdadeiro código geral de condutas, na medida em que impõe limites à gestão pública, estabelece sanções

\footnotetext{
${ }^{34}$ OSÓRIO, Fábio Medina. Teoria da Improbidade Administrativa: má gestão: corrupção: ineficiência. São Paulo: Revista dos Tribunais, 2013, p. 101.

${ }^{35}$ SIMÃO NETO, Calil. Improbidade Administrativa: teoria e prática. Leme: J. H. Mizuno, 2014.
} 
e limita o jus puniendi do Estado. ${ }^{36}$ No que tange às condutas que limitam a atuação pública, tal código geral as distribuiu em três grandes blocos. 0 primeiro trata de condutas que geram o enriquecimento ilícito, o segundo de condutas que acarretam danos ao erário e o terceiro versa sobre condutas violadoras de princípios da Administração Pública. Cada bloco de condutas expressa rol exemplificativo e não taxativo. Nas palavras de Osório, a LIA abre para "enorme quantidade de modelos de condutas proibidas, a partir de processos interpretativos quase infinitos". ${ }^{37}$

A metodologia da Lei, dividida em três grandes blocos de condutas interligados por um único sentido, confere a ela a forma de sistema normativo. Com efeito, ao mesmo tempo em que a Lei de Improbidade brasileira estabelece três grandes blocos de condutas, tais blocos estabelecem relações internas entre si. Além disso, conforme explica Medina, a LIA "perfectibiliza-se a partir de normas sancionadoras em branco"38, que se integram e a complementam, e não pela sua incidência direta. Diferentes combinações internas como também a complementação da LIA por outras normas perfectibilizam condutas jurídicas ímprobas. Nesse sentido, tentamos representar a estrutura e dinâmica da Lei 8.429/92:

Figura 1 - Sistema de Improbidade Administrativa brasileiro

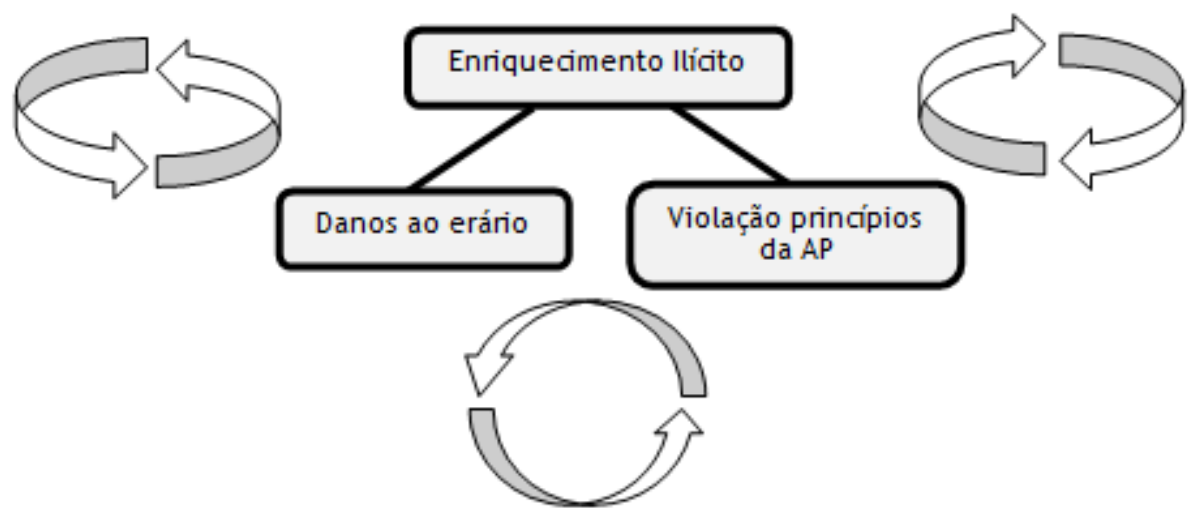

Fonte: autores (2016).

Em face dessa organização estrutural e das relações sistemáticas, as sanções estabelecidas devem ser sempre aplicadas de modo graduado, observado o escalonamento de

\footnotetext{
${ }^{36}$ OSÓRIO, Fábio Medina. Teoria da Improbidade Administrativa: má gestão: corrupção: ineficiência. São Paulo: Revista dos Tribunais, 2013.

${ }^{37}$ Ibidem. p. 208.

${ }^{38}$ Ibidem. p. 384.
} 
condutas e a extensão do dano causado bem como de proveito patrimonial obtido, se houver. Isto porque a LIA enfrenta de forma dinâmica o desafio da tensão entre a segurança jurídica e a efetividade punitiva, jogo que visa evitar discricionariedades interpretativas, banalização da aplicação da Lei e, consequentemente, o aumento da impunidade. Ao passo que o diploma legal abre uma possibilidade de interpretações de condutas violadoras da moralidade administrativa, impõe limites e critérios subjetivos a serem observados.

Com efeito, ao passo que a Constituição Federal de 1988 e a Lei de Improbidade Administrativa estabeleceram sanções gravíssimas, tais como a suspensão dos direitos políticos, perda de função pública, indisponibilidade dos bens, ressarcimento ao erário, perda de bens ou valores acrescidos ilicitamente ao patrimônio, pagamento de multa civil e proibição de contratar com o Poder Público ou receber benefícios ou incentivos fiscais ou creditícios, a responsabilidade delineada pela LIA não é de natureza objetiva. Ou seja, não basta ao agente praticar uma conduta tipificada no diploma legal para a comissão de ato de improbidade, haja vista a imprescindibilidade de que a conduta seja acompanhada de elemento subjetivo, expresso pelo dolo, em todos os tipos de conduta e, no caso do bloco de condutas que geram lesão ao erário, também admitida a culpa. A culpa, neste caso, caracterizada por ação negligente, imprudente ou imperita, comprovadamente relacionada à violação do dever de probidade normatizado.

A LIA, ao admitir condutas culposas, estendeu sua incidência não só às desonestidades, mas também às graves ineficiências que atingem o campo da ética pública. Em face disso é que Osório, atribuindo à improbidade administrativa o conceito de modalidade de má-gestão pública, fundamenta que a corrupção é somente uma das faces da improbidade, haja vista que a mesma atinge também graves e inescusáveis ineficiências, que, reiteradas, acabam por transformar-se em desonestidades e verdadeiros ilícitos. ${ }^{39}$

Também releva dizer que o código geral de condutas estabelecido pela LIA ultrapassou a proteção à má utilização de recursos públicos, eis que previu bloco de condutas que atentam contra os princípios da Administração Pública, que constituam ação ou omissão violadora dos deveres de honestidade, imparcialidade, legalidade e lealdade às instituições, sem que haja necessidade de ofensa ao patrimônio público. Ou seja, a LIA tratou de proteger não somente o patrimônio material, mas também o patrimônio imaterial do Estado, a moralidade administrativa em si, a ética pública. A pura violação de princípios da Administração, desde que preenchidos

${ }^{39}$ OSÓRIO, Fábio Medina. Teoria da Improbidade Administrativa: má gestão: corrupção: ineficiência. São Paulo: Revista dos Tribunais, 2013. 
requisitos objetivos - a conduta - e subjetivos - dolo comprovado -, ainda que não haja prejuízos patrimoniais, caracterizará ato de improbidade administrativa. Por essa razão é que as condutas que violam os princípios da Administração Pública são consideradas regra de reserva. A proteção que a Lei oferece é ao dever de probidade, o agir ético com a coisa pública.

Nas palavras do Professor Juarez Freitas:

Sob a ótica da Lei, ainda quando não se verifique o enriquecimento ilícito ou o dano material, a violação do princípio da moralidade pode e deve ser considerada, em si mesma, apta para caracterizar a ofensa ao subprincípio da probidade administrativa, na senda correta de perceber que o constituinte quis coibir a lesividade à moral positivada, em si mesma, inclusive naqueles casos em que se não se vislumbram, incontrovertidos, os danos materiais. ${ }^{40}$

Cabe observar que a LIA constitui um código geral de condutas de sujeição geral, na medida em que, embora para a caracterização de ato improbidade seja necessária a participação de um agente público, abrangidas todas as categorias, inclusive a dos agentes políticos conforme bem aborda Decoiman ${ }^{41}$, o diploma legal estabelece seu alcance a toda e qualquer pessoa que concorrer para a prática de conduta ímproba. A LIA estende a responsabilidade administrativa e político-administrativa para a coparticipação de terceiros relacionados à utilização da coisa pública, estes ficando sujeitos às mesmas sanções previstas na Lei 8.429/92. 0 artigo $3^{\circ}$ do diploma legal estabelece que suas disposições são aplicáveis:

àquele que, mesmo não sendo agente público, induza ou concorra para a prática do ato de improbidade ou dele se beneficie sob qualquer forma direta ou indireta". ${ }^{42} \mathrm{Na}$ continuidade, o artigo $4^{\circ}$ prescreve que "os agentes públicos de qualquer nível ou hierarquia são obrigados a velar pela estrita observância dos princípios de legalidade, impessoalidade, moralidade e publicidade no trato dos assuntos que the são afetos. ${ }^{43}$

Em face da sujeição universal de todos os agentes públicos, de qualquer categoria e hierarquia, Osório afirma seu poder de autovinculação pela autodisciplina:

\footnotetext{
${ }^{40}$ FREITAS, Juarez. Do princípio da probidade administrativa e de sua máxima efetivação. Revista de Direito Administrativo, Rio de Janeiro, v. 204, p. 65-84, fev. 2015.

${ }^{41}$ DECOMAIN, Paulo Roberto. Improbidade administrativa. São Paulo: Dialética, 2007.

42 BRASIL. Lei № 8.429, de 2 de junho de 1992. Ementa: Dispõe sobre as sanções aplicáveis aos agentes públicos nos casos de enriquecimento ilícito no exercício de mandato, cargo, emprego ou função na administração pública direta, indireta ou fundacional e dá outras providências. Diário Oficial [da] República Federativa do Brasil, Poder Executivo, Brasília, DF, 03 jun. 1992, Seção 1, p. 6995.

${ }^{43}$ BRASIL. Lei № 8.429, de 2 de junho de 1992. Ementa: Dispõe sobre as sanções aplicáveis aos agentes públicos nos casos de enriquecimento ilícito no exercício de mandato, cargo, emprego ou função na administração pública direta, indireta ou fundacional e dá outras providências. Diário Oficial [da] República Federativa do Brasil, Poder Executivo, Brasília, DF, 03 jun. 1992, Seção 1, p. 6995.
} 
Induvidoso que o tema da autorregulação ou autodisciplina expõe o problema da responsabilidade moral do indivíduo. Esse tipo de responsabilidade é muito positivo, já que constitui um fortalecimento dos valores éticos em uma organização. Como já se disse alhures, a autodisciplina põe de relevo a autovinculação a deveres. Talvez aí resida o fator preponderante no cumprimento das normas: a autodisciplina. ${ }^{44}$

Como ressalta o autor, significa uma universalização do princípio da responsabilidade. E, ao sujeitar a todos, também requer o controle de todos sobre as atividades públicas.

Com base nos elementos doutrinários até aqui traçados, que conformam o sistema de improbidade administrativa brasileiro, procura-se verificar se tal sistema de improbidade, pela sua funcionalidade e estrutura oferece instrumentalização efetiva para a prevenção de boas práticas, no campo da moralidade administrativa.

\section{O SISTEMA DE IMPROBIDADE ADMINISTRATIVA BRASILEIRO É MECANISMO PREVENTIVO À BOA ADMINISTRAÇÃO PÚBLICA?}

O percurso traçado até aqui nos permite consolidar a ideia de que a Constituição Federal de 1988 promoveu importante renovação no trato da improbidade administrativa no Brasil, ao regulamentar uma ética pública operacionalizada a partir do princípio da moralidade administrativa integrada à legalidade.

Ao regulamentar a ética pública, a Carta Magna brasileira de 1988 trouxe a responsabilidade dos agentes públicos por condutas inadequadas ao campo do direito administrativo, que incide sobre fenômenos sistêmicos da gestão pública, os quais antes não eram abrangidos pelo sistema do direito penal, permitindo maior eficácia na orientação e na organização de condutas e processos próprios à Administração Pública.

Nesse sentido, é possível verificar que seguindo as tendências mais modernas, a Constituição Federal brasileira de 1988 avançou para atuação mais preventiva no que toca à proteção da probidade administrativa. Esse avanço constitucional brasileiro, referido pelos doutrinadores administrativistas, permitiu ao legislador federal a elaboração de uma Lei de Improbidade Administrativa geral, estruturada na forma de um código de condutas, o qual, ao

${ }^{44}$ OSÓRIO, Fábio Medina. Teoria da Improbidade Administrativa: má gestão: corrupção: ineficiência. São Paulo: Revista dos Tribunais, 2013, p. 180. 
mesmo tempo em que é aberto, limita as ações dos agentes públicos, oportunizando uma prática educativa no campo da moralidade pública.

Além de a Lei de Improbidade Administrativa brasileira ter colocado em jogo a responsabilidade por tipos relevantes ao direito administrativo, campo específico à orientação da atividade pública, consolidou-se como mecanismo atuante no controle da ética e, por conseguinte, como instrumento educativo para a formação de agentes públicos. Ressalta-se aqui a lição de Cassese $^{45}$, de que a constitucionalização de princípios da administração pública, tais como a moralidade administrativa, levou à legalização da administração pública. Nessa esteira, os deveres de probidade passaram a ser obrigações reais.

Ressalta dizer que, sob a égide de um código geral de condutas, a LIA exerce função sistematizadora de regras administrativas legais, cujo objeto central é a regulação de condutas incidentes a todos os agentes públicos. É um código geral no campo da ética, que visa à segurança e à racionalidade da atividade pública, conduzidas pelo dever de diligência.

A condição de código geral, ainda que por regras de proibição, normatiza ideais do sistema pela fixação de condutas gerais, que servem à prevenção de transgressões. Osório ${ }^{46}$ afirma que os tipos abstratos previstos na LIA traduzem a ideia de igualdade e responsabilidade, preservando um núcleo básico de responsabilidades dos agentes públicos. Nesse diapasão, a LIA universaliza o princípio de responsabilidade, ao qual o setor público adere pelo compromisso pessoal, o que sem dúvida leva a um processo de autoeducação.

O componente subjetivo da culpa, para a caracterização de responsabilidade, também pode ser visto como boa medida a um controle preventivo, eis que direciona os agentes a comportamentos diligentes. Diferente do dolo, que revela uma intenção, a culpa é ingrediente que direciona a resultado não querido, que faz ressaltar a necessidade de observância de condutas diligentes no caminho a ser percorrido para o alcance do interesse público.

Destarte, a partir da estrutura, funcionalidade, conteúdo, abrangência e unicidade, o sistema brasileiro de proteção à probidade administrativa, com a Lei de Improbidade Administrativa, materializa-se como verdadeira ferramenta de controle, adquirindo função preventiva e educativa no campo da ética pública.

\footnotetext{
45 CASSESE, Sabino. Il diritto alla buona amministrazione. Rivista Europea di Diritto Pubblico. Reino Unido, v. 21, n. 3, p. 1037-1047, 2009.

${ }^{46}$ OSÓRIO, Fábio Medina. Teoria da Improbidade Administrativa: má gestão: corrupção: ineficiência. São Paulo: Revista dos Tribunais, 2013.
} 


\section{CONCLUSÃO}

O presente trabalho travou a proposta de analisar a possivel funcionalidade do sistema de probidade administrativa brasileiro para a prevenção de condutas a uma boa administração. Boa administração aqui focada não somente na eficiência, mas sobretudo na ética administrativa pública, balizada pela Constituição Federal brasileira de 1988, diante da positivação da moralidade administrativa e do dever de probidade. Nesse particular, a prevenção da probidade administrativa pautada pelo sistema jurídico, considerada sua conformação e dinâmica. De modo que oportunize não apenas a sanção, mas a partir de força educativa ofereça possibilidade ao controle prévio e voluntário às más condutas no campo ético-administrativo. A via normativa funcionando como instrumento educativo apto a direcionar e prevenir comportamento éticonormativo natural e volitivo dos agentes públicos brasileiros, nas mais diversas categorias e hierarquias. O sistema jurídico visando não exclusivamente à punição, mas à construção da autodisciplina e do autocontrole no exercício da atividade pública.

Nesse percurso, abordaram-se as categorias que conformam o sistema de probidade administrativa a partir da Constituição Federal e da Lei de Improbidade Administrativa. E tais categorias, na medida em que constituem os vetores à construção legal do referido sistema, dadas as definições e relações entre moralidade administrativa e probidade administrativa.

O estudo permitiu traçar a evolução da moralidade administrativa de atributo interno à administração pública, via legalidade, à positivação da moralidade administrativa pela previsão legal do que não é ético-administrativo. Com efeito, considerando que os destinatários do sistema de probidade, a priori, são os agentes públicos na sua ampla definição, a Lei de Improbidade Administrativa tratou de exemplificar condutas que escapam ao comportamento ético-administrativo, traçando verdadeira orientação de cunho pedagógico àqueles que praticam a atividade administrativa.

A Lei de Improbidade Administrativa, instrumento por excelência de proteção à probidade no Direito Administrativo brasileiro, funcionalmente interligada a outras normas jurídicas para sua concretização, estabelece claro direcionamento à satisfação de interesses da coletividade pública, mediante orientação a condutas subjetivas pautadas pela diligência, honestidade e lealdade à atividade pública, de forma exemplificativa. O campo central constitucional, com densidade legal ordinária instituída por um código geral de condutas - LIA - 
compatibilizado à legislação e à tendência internacional, criou um sistema de proteção que ultrapassa valor normativo repressivo, claramente progredindo à causa preventiva pelo poder de instrumental educativo.

Com efeito, a análise da Lei de Improbidade Administrativa baseada no seu aspecto estrutural e funcional, a partir dos elementos de materialidade, forma e vinculação, traduz elenco de diretrizes gerais e pontos de regulação sistêmica universal, que possibilitam o fortalecimento de comportamentos compatíveis à ética pública. A LIA consolidou densidade jurídica a princípios jurídicos constitucionais, fortalecendo o campo da educação subjetiva de autodisciplina e de autocontrole no exercício prático da administração pública.

A partir da função integrativa da LIA ao dispositivo constitucional, ela transfere ao agente público, elemento humano, a obrigação de cuidar e garantir a eficácia dos princípios constitucionais. A LIA fala direta e imediatamente ao elemento humano da atividade administrativa, o qual, nos dizeres de Peter Häberle, tem obrigação de estarem aptos a interpretá-la:

Todo aquele que vive no contexto regulado por uma norma e que vive com esse contexto é, indireta ou até mesmo diretamente, um intérprete dessa norma. De tal arte que o destinatário da norma é participante ativo, muito mais ativo do que se pode supor tradicionalmente, do processo hermenêutico. ${ }^{47}$

Freitas, mesmo que reforçando o caráter repressivo da Lei de Improbidade Administrativa, destaca “[...] no sentido preventivo e repressivo, na linha do resguardo, em última análise, do princípio superior da moralidade". ${ }^{48}$ E é por isso que Arnaldo Rizzardo e Fábio Medina Osório afirmam, respectivamente, que a Lei de Improbidade Administrativa brasileira representa uma conscientização de deveres éticos e significa instrumento de combate às más condutas, consolidando uma ética republicana no setor público, o que este trabalho reforça, ocorre também pela sua condução pedagógica.

De forma que, respondendo ao questionamento proposto, é possível afirmar que o sistema jurídico de probidade administrativa também contribui para a prevenção de condutas ímprobas.

\footnotetext{
${ }^{47}$ Apud FAZZIO JR. Atos de Improbidade Administrativa: doutrina, legislação e jurisprudência. São Paulo: Atlas, 2007, p. 37.

48 FREITAS, Juarez. Do princípio da probidade administrativa e de sua máxima efetivação. Revista de Direito Administrativo, Rio de Janeiro, v. 204, p. 65-84, fev. 2015.
} 


\section{REFERÊNCIAS}

BAHENA, Kele Cristiani Diogo. 0 princípio da moralidade administrativa e seu controle pela Lei de Improbidade. Curitiba: Juruá, 2010.

BASTOS, Rosaura Moreira Brito. Improbidade Administrativa - conteúdo jurídico e dimensão constitucional. Belo Horizonte: Fórum, 2010.

BRASIL. Constituição Federal. Brasília: Senado Federal, 1988. Disponível em: <http://www.planalto.gov.br/ccivil_03/constituicao/constituicaocompilado.htm>. Acesso em: 10 mai. 2016.

BRASIL. Lei № 8.429, de 2 de junho de 1992. Dispõe sobre as sanções aplicáveis aos agentes públicos nos casos de enriquecimento ilícito no exercício de mandato, cargo, emprego ou função na administração pública direta, indireta ou fundacional e dá outras providências. In Diário Oficial [da] República Federativa do Brasil, Poder Executivo, Brasília, DF, 03 jun. 1992, Seção 1, p. 6995. Disponível em: <http://www.planalto.gov.br/ccivil_03/leis/L8429.htm>. Acesso em: 10 mai. 2016.

CASSESE, Sabino. Il diritto alla buona amministrazione. Rivista Europea di Diritto Pubblico. Reino Unido, v. 21, n. 3, p. 1037-1047, 2009.

DECOMAIN, Paulo Roberto. Improbidade administrativa. São Paulo: Dialética, 2007.

FAZZIO JÚNIOR, Waldo. Atos de Improbidade Administrativa: doutrina, legislação e jurisprudência. São Paulo: Atlas, 2007.

FREITAS, Juarez. O Controle dos Atos Administrativos e os princípios fundamentais. 2. ed., São Paulo: Malheiros Editora, 1999.

FREITAS, Juarez. Do princípio da probidade administrativa e de sua máxima efetivação. Revista de Direito Administrativo, Rio de Janeiro, v. 204, p. 65-84, fev. 2015. ISSN 2238-5177. Disponível em: <http://bibliotecadigital.fgv.br/ojs/index.php/rda/article/view/46754/46380>. Acesso em: 12 jul. 2016. DOI: <http://dx.doi.org/10.12660/rda.v204.1996.46754>.

GIACOMUZZI, José Guilherme. A moralidade administrativa e a boa-fé da administração pública (o conteúdo dogmático da moralidade administrativa). São Paulo: Malheiros, 2002.

MARTINS, Fernando Rodrigues. Controle do Patrimônio Público: comentários à Lei de Improbidade Administrativa. São Paulo: RT, 2010.

MARTINS JR, Wallace Paiva. Probidade Administrativa. São Paulo: Saraiva, 2009.

MATTARELLA, Bernardo Giorgio. Recenti tendenze legislative in materia di prevenzione della corruzione. Giornale di diritto amministrativo. Milano, v. 2, 2012.

MEDAUAR, Odete. Direito Administrativo Moderno. São Paulo: Revista dos Tribunais, 2010. 
OSÓRIO, Fábio Medina. Teoria da Improbidade Administrativa: má gestão: corrupção: ineficiência. São Paulo: Revista dos Tribunais, 2013.

PAZAGLINI FILHO, Marino; ROSA, M. F. E; FAZZIO JÚNIOR, Waldo. Improbidade Administrativa: aspectos jurídicos da defesa do patrimônio público. São Paulo: Atlas, 1999.

PETRELLUZZI, Marcos Vinícius; RIZEK JUNIOR, Rubens Naman. Lei anticorrupção: origens, comentários e análise da legislação correlata. São Paulo: Saraiva, 2014.

RIZZARDO, Arnaldo. Ação civil pública e ação de improbidade administrativa. Rio de Janeiro: Forense, 2014.

SIMÃO NETO, Calil. Improbidade Administrativa: teoria e prática. Leme: J. H. Mizuno, 2014.

Recebido em: 25/07/016 / Revisões requeridas em: 21/11/2016 / Aprovado em: 01/02/2017 